\title{
Phase Transfer Catalysis; Nucleophilic Substitution of $\beta$-Bromohydrins with Anions in Solid-Liquid System
}

\author{
Norio Uchida, * Yosuke NakajIma, Jun'ichi Oda, and Yuzo InouYe \\ Institute for Chemical Research, Kyoto University, Uji, Kyoto 611 \\ *Fumakilla Co., Ltd., Ohno-Cho, Saeki-Gun, Hiroshima-Ken 739-04
}

Received June 4, 1979

\begin{abstract}
Nucleophilic displacements of $\beta$-bromohydrins with azide, phthalimide, acetate and thiocyanate anions were effected by tetramethylethylenediamine (TMEDA), triethylenediamine (TEDA) and 18-crown-6 (CE) in solid-liquid media, to afford the products in various yields and distributions.
\end{abstract}

Phase transfer catalysis is being extensively utilized as a versatile, simple and attractive synthetic means. ${ }^{11}$ In the previous papers, ${ }^{2)}$ we described the azidation of bromohydrins in two-phase media, and demonstrated that the reaction proceeds with complete regiospecificity via an $S_{\mathrm{N}} 2$ process, in which neighboring oxygen functions play an important role in the reaction.

As an extension of our work, it seemed of interest to undertake the reaction of bromohydrins with several anions other than azide anion and to compare the catalytic efficiency of diamines with that of 18-crown-6. Di- and polyamines, also employed as catalysts in the same manner, have not yet been so extensively explored as the other catalysts. We now wish to report the results of studies dealing with the reaction of methyl $\beta$-methoxy- and $\beta$ hydroxy- $\alpha$-bromopropionates 1 and 2 and styrene bromohydrin 3 with anions such as azide, phthalimide, acetate and thiocyanate, catalyzed by TMEDA, TEDA and CE in solid-liquid system.

\section{RESULTS AND DISCUSSION}

\section{Reaction of sodium azide}

Both bromohydrins 1 and 2 reacted with sodium azide under solid-liquid system in the presence of TMEDA or TEDA to give serine 4 as the sole product after subsequent reduction of the intermediary azides (Table I). The yields were of the same order as those previously obtained by the use of $\mathrm{CE}$ as PTC. It then seems that diamines and $\mathrm{CE}$ conferred a comparable nucleophilicity to azide anion. The observed formation of isoserine 5 in the reaction by the use of TEDA in benzene (run 6 ) may be ascribed to the process which might proceed through the intermediate formation of methyl glycidate generated by the action of slightly basic catalysts, followed by the nucleophilic attack at $\beta$-carbon of oxirane.

In the azide substitution on styrene bromohydrin 3 under the same conditions, an appreciable amount of the rearrangement product 7 was detected, together with the direct displacement product 6 (Table II). This is also probably due to the intervention of pathway via styrene oxide because of the basicity of catalysts. Acetonitrile and DME were preferred as solvent to benzene because of their dissociating ability.

\section{Reaction of potassium phthalimide}

Amino acid $\mathbf{4}$ was formed from the substrate 1 in the range of chemical yield $74 \sim 78 \%$ in acetonitrile and $45 \sim 57 \%$ in benzene (runs $7 \sim 12$ in Table I). However, the treatment of 2 with phthalimide anion resulted in the formation of a mixture of products which could not be separated. Only in the reaction of styrene bromohydrin 3 with CE used as catalyst, styrene oxide was detected $(66 \%)$ in the reaction mixture (run 7 in Table II). This may be 
TABLE I. NUCLEOPHILIC SUbSTITUTION OF $\beta$-Methoxy- OR $\beta$-Hydroxy- $\alpha$ Bromopropionates under Solid-Liquid Phase Transfer Conditions

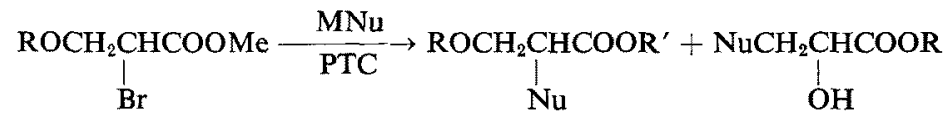
$1 ; \mathrm{R}=\mathrm{CH}_{3}$
4; $\mathrm{R}=\mathrm{R}^{\prime}=\mathrm{H}, \mathrm{Nu}=\mathrm{NH}_{2}$
$5 ; \mathbf{R}=\mathrm{H}, \mathrm{Nu}=\mathrm{NH}_{2}$
$2 ; \mathrm{R}=\mathrm{H}$
$8 ; \mathrm{R}=\mathrm{R}^{\prime}=\mathrm{Me}, \mathrm{Nu}=\mathrm{OAc}$
$11 ; R=R^{\prime}=\mathrm{Me}, \mathrm{Nu}=\mathrm{SCN}$

\begin{tabular}{|c|c|c|c|c|c|c|c|}
\hline Run & Sub. ${ }^{c}$ & $\mathrm{MNu}$ & PTC $^{a}$ & Solvent & Temp/Time & Products & $\%$ Yield \\
\hline $1^{a}$ & 1 & $\mathrm{NaN}_{3}{ }^{d}$ & TMEDA & $\mathrm{CN}_{3} \mathrm{CN}$ & $80^{\circ} \mathrm{C} / 17 \mathrm{~h}$ & $4^{n}$ & 87 \\
\hline 2 & 1 & $\mathrm{NaN}_{3}$ & TEDA & $\mathrm{CH}_{3} \mathrm{CN}$ & $80^{\circ} \mathrm{C} / 17 \mathrm{~h}$ & 4 & 65 \\
\hline 3 & 2 & $\mathrm{NaN}_{3}$ & TMEDA & $\mathrm{CH}_{3} \mathrm{CN}$ & $80^{\circ} \mathrm{C} / 17 \mathrm{~h}$ & 4 & 70 \\
\hline 4 & 2 & $\mathrm{NaN}_{3}$ & TEDA & $\mathrm{CH}_{3} \mathrm{CN}$ & $80^{\circ} \mathrm{C} / 17 \mathrm{~h}$ & 4 & 48 \\
\hline 5 & 2 & $\mathrm{NaN}_{3}$ & TMEDA & $\mathrm{C}_{6} \mathrm{H}_{6}$ & $80^{\circ} \mathrm{C} / 17 \mathrm{~h}$ & 4 & 69 \\
\hline 6 & 2 & $\mathrm{NaN}_{3}$ & TEDA & $\mathrm{C}_{8} \mathrm{H}_{8}$ & $80^{\circ} \mathrm{C} / 17 \mathrm{~h}$ & $4(87): 5(13)^{i}$ & 45 \\
\hline $7^{b}$ & 1 & $\mathrm{KPI}^{\mathrm{e}}$ & TMEDA & $\mathrm{CH}_{3} \mathrm{CN}$ & $80^{\circ} \mathrm{C} / 2 \mathrm{~h}$ & 4 & 78 \\
\hline 8 & 1 & KPI & TEDA & $\mathrm{CH}_{3} \mathrm{CN}$ & $80^{\circ} \mathrm{C} / 2 \mathrm{~h}$ & 4 & 74 \\
\hline 9 & 1 & KPI & $\mathrm{CE}$ & $\mathrm{CH}_{3} \mathrm{CN}$ & $80^{\circ} \mathrm{C} / 2 \mathrm{~h}$ & 4 & 76 \\
\hline 10 & 1 & KPI & TMEDA & $\mathrm{C}_{8} \mathrm{H}_{6}$ & $80^{\circ} \mathrm{C} / 2 \mathrm{~h}$ & 4 & 57 \\
\hline 11 & 1 & KPI & TEDA & $\mathrm{C}_{8} \mathrm{H}_{6}$ & $80^{\circ} \mathrm{C} / 2 \mathrm{~h}$ & 4 & 45 \\
\hline 12 & 1 & KPI & $\mathrm{CE}$ & $\mathrm{C}_{8} \mathrm{H}_{8}$ & $80^{\circ} \mathrm{C} / 2 \mathrm{~h}$ & 4 & 48 \\
\hline 13 & 1 & $\mathrm{KOAc}^{f}$ & TMEDA & $\mathrm{CH}_{3} \mathrm{CN}$ & $80^{\circ} \mathrm{C} / 1.5 \mathrm{~h}$ & 8 & 93 \\
\hline 14 & 1 & KOAc & $\mathrm{CE}$ & $\mathrm{CH}_{3} \mathrm{CN}$ & $80^{\circ} \mathrm{C} / 1.5 \mathrm{~h}$ & 8 & 89 \\
\hline 15 & 1 & $\mathrm{KSCN}^{f}$ & TMEDA & $\mathrm{CH}_{3} \mathrm{CN}$ & $80^{\circ} \mathrm{C} / 0.5 \mathrm{~h}$ & 11 & 83 \\
\hline 16 & 1 & $\mathrm{KSCN}$ & TEDA & $\mathrm{CH}_{3} \mathrm{CN}$ & $80^{\circ} \mathrm{C} / 0.5 \mathrm{~h}$ & 11 & 74 \\
\hline 17 & 1 & $\mathrm{KSCN}$ & $\mathrm{CE}$ & $\mathrm{CH}_{3} \mathrm{CN}$ & $80^{\circ} \mathrm{C} / 0.5 \mathrm{~h}$ & 11 & 74 \\
\hline
\end{tabular}

${ }^{a}$ The reactions were run $(1 \sim 6)$ with $7.5 \mathrm{ml}$ of solvent per $5 \mathrm{mmol}$ of substrate. ${ }^{b} 3 \mathrm{mmol}$ of substrate (runs 7 17). ${ }^{o}$ Sub.: substrate. ${ }^{d}$ Equimolar to substrate. ${ }^{\theta} \mathrm{KPI}$ : Potassium phthalimide. ${ }^{f} 1.2$ mole equivalent to substrate. ${ }^{g} 0.1$ molar equivalent. ${ }^{n}$ The product serine 4 was isolated by the usual work up. ${ }^{2)}{ }^{i}$ The ratio of serine: isoserine was determined by PMR. ${ }^{2)}{ }^{j}$ Isolation yicld.

attributable to dehydrobromination which might possibly arise from the operation of phthalimide anion as base rather than nucleophile.

\section{Reaction of potassium acetate}

Exclusive formation of $O$-acetylated compound 8 was observed in the reaction of potassium acetate with the substrate 1 in 93 and $89 \%$ yields by the use of either TMEDA or CE as catalyst respectively (runs 13 and 14 in Table I). On the other hand, the reaction of styrene bromohydrin gave the rearrangement product $10^{4)}$ in $25 \sim 33 \%$ along with the substitution compound 9 (runs $8 \sim 11$ in Table II), as was the case in the reaction with sodium azide. These results suggest the possible intervention of styrene oxide, because the basicity of acetate anion is comparable with that of phthalimide. Actually, the increase in styrene oxide with decrease in the substrate was confirmed by means of NMR-monitoring.

In order to get insight into this nucleophilic reaction, styrene oxide was treated with an equimolar acetic acid and 0.2 molar potassium acetate in the presence or absence of $\mathrm{CE}$. Nearly the same product distribution was obtained as those found for the bromohydrin 3 with catalyst. This finding shows that the catalyst does not participate in the cleavage of oxirane to afford the products 9 and 10. It seems reasonable to assume that the catalyst operates as transporter of anion to the organic phase and enhances the basicity of anion, since, without catalyst, the reaction did not take place at all and the substrate was recovered as such.

\section{Reaction of potassium thiocyanate}

A regiospecific reaction is plausible at the soft sulfur and the hard nitrogen termini. ${ }^{5)}$ 
Table II. Reaction of Styrenebromohydrin in the Presence of PTC

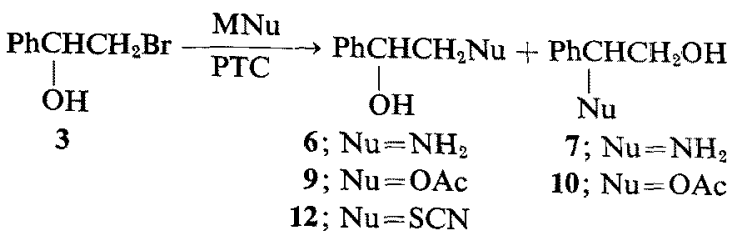

\begin{tabular}{|c|c|c|c|c|c|c|c|}
\hline Run & PTC & $\mathrm{MNu}^{a}$ & Solvent & Temp/Time & Product & $\%$ Yield $^{d}$ & Ratio $^{e}$ \\
\hline 1 & TMEDA & $\mathrm{NaN}_{3}$ & $\mathrm{C}_{6} \bar{H}_{6}$ & $80^{\circ} \mathrm{C} / 17 \mathrm{~h}$ & $6: 7^{\circ}$ & 28 & $72: 28$ \\
\hline 2 & TEDA & $\mathrm{NaN}_{3}$ & $\mathrm{C}_{6} \mathrm{H}_{6}$ & $80^{\circ} \mathrm{C} / 17 \mathrm{~h}$ & $6: 7$ & 16 & $64: 36$ \\
\hline 3 & TMEDA & $\mathrm{NaN}_{3}$ & DME & $80^{\circ} \mathrm{C} / 17 \mathrm{~h}$ & $6: 7$ & 92 & $78: 22$ \\
\hline 4 & TEDA & $\mathrm{NaN}_{3}$ & DME & $80^{\circ} \mathrm{C} / 17 \mathrm{~h}$ & $6: 7$ & 74 & $78: 22$ \\
\hline 5 & TMEDA & $\mathrm{NaN}_{3}$ & $\mathrm{CH}_{3} \mathrm{CN}$ & $80^{\circ} \mathrm{C} / 17 \mathrm{~h}$ & $6: 7$ & 93 & $73: 27$ \\
\hline 6 & TEDA & $\mathrm{NaN}_{3}$ & $\mathrm{CH}_{3} \mathrm{CN}$ & $80^{\circ} \mathrm{C} / 17 \mathrm{~h}$ & $6: 7$ & 93 & $75: 25$ \\
\hline 7 & $\mathrm{CE}$ & $\mathrm{KPI}^{b}$ & $\mathrm{CH}_{3} \mathrm{CN}$ & $80^{\circ} \mathrm{C} / 24 \mathrm{~h}$ & styrene oxide & 66 & - \\
\hline 8 & TMEDA & KOAc & $\mathrm{CH}_{3} \mathrm{CN}$ & $80^{\circ} \mathrm{C} / 17 \mathrm{~h}$ & $9: 10$ & 41 & $75: 25$ \\
\hline 9 & $\mathrm{CE}$ & KOAc & $\mathrm{CH}_{3} \mathrm{CN}$ & $80^{\circ} \mathrm{C} / 17 \mathrm{~h}$ & $9: 10$ & 46 & $74: 26$ \\
\hline 10 & TMEDA & KOAc & $\mathrm{C}_{8} \mathrm{H}_{8}$ & $80^{\circ} \mathrm{C} / 17 \mathrm{~h}$ & $9: 10$ & 39 & $67: 33$ \\
\hline 11 & $\mathrm{CE}$ & KOAc & $\mathrm{C}_{6} \mathrm{H}_{\mathrm{B}}$ & $80^{\circ} \mathrm{C} / 17 \mathrm{~h}$ & $9: 10$ & 35 & $72: 28$ \\
\hline 12 & - & KOAc & $\mathrm{CH}_{3} \mathrm{CN}$ & $80^{\circ} \mathrm{C} / 17 \mathrm{~h}$ & - & 0 & - \\
\hline 13 & TMEDA & $\mathrm{KSCN}$ & $\mathrm{CH}_{3} \mathrm{CN}$ & $80^{\circ} \mathrm{C} / 4 \mathrm{~h}$ & 13 & 42 & - \\
\hline 14 & TEDA & $\mathrm{KSCN}$ & $\mathrm{CH}_{3} \mathrm{CN}$ & $80^{\circ} \mathrm{C} / 4 \mathrm{~h}$ & 13 & 40 & - \\
\hline 15 & $\mathrm{CE}$ & $\mathrm{KSCN}$ & $\mathrm{CH}_{3} \mathrm{CN}$ & $80^{\circ} \mathrm{C} / 0.5 \mathrm{~h}$ & 12 & 74 & - \\
\hline
\end{tabular}

Reaction of 1 with potassium thiocyanate under PTC conditions afforded exclusively the thiocyanate 11 (runs $15 \sim 17$ in Table I), in which the softer carbon center bonded to the soft sulfur end. On the other hand, interestingly the reaction of 3 with thiocyanate resulted in the formation of the different compounds by a catalyst employed for the reaction; i.e., the diamine-catalyzed reaction gave the thiirane $\mathbf{1 3}$ as the sole product (runs 13 and 14 in Table II), whereas that of $C E$ yielded exclusively the thiocyanate $\mathbf{1 2}$ in high yield without any detectable formation of other products (run 15 in Table II). The formation of thiirane $\mathbf{1 3}$ in the former reaction may possibly be due to the path

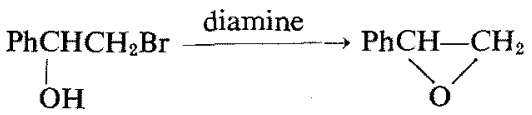

3

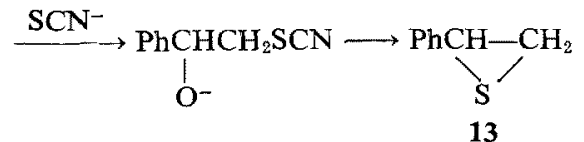

Scheme 1 involving the initial formation of intermediate oxirane, followed by the known conversion processes $^{7)}$ to the end product (Scheme 1). The latter procedure provides a simple method for the preparation of thiocyanate derivatives.

In conclusion, diamines are almost as effective as $\mathrm{CE}$ for phase transfer catalysis in nucleophilic displacements of bromides. Because of the dual behaviors of the diamine catalysts, the basicity should be taken in account for the substrates with polar functions such as hydroxyl group, and the basicity of the nucleophile actually affected the reaction pathway. In general, the nucleophilic displacements took place readily with softer anions such as azide and thiocyanate under those conditions adopted here.

\section{EXPERIMENTAL}

Analytical instruments used were a Varian Model EM-360 or JEOL JNM-100 nuclear magnetic resonance spectrometer for NMR, a Hitachi 215 grating spectrophotometer for IR, JEOL JMS-01SG mass 
spectrometer for Mass spectra and a Shimazu G4-4B gas chromatograph for GLC.

Materials. Catalysts and inorganic salts were analytical grade commercial products used without further purification. Styrene bromohydrin was used after purification of commercial product; $\alpha$-bromopropionates were prepared according to the known procedure. ${ }^{2)}$ Authentic samples were also obtained according to the procedures in the literature.

The reaction was carried out by the literature procedure $^{\text {8) }}$ with slight modification.

Reaction of $\beta$-methoxy- $\alpha$-borompropionate $I$ with potassium phthalimide; Typical procedure (Table 1).

To potassium phthalimide $(694.6 \mathrm{mg}, 3.75 \mathrm{mmol})$ in dry solvent (acetonitrile or benzene, $3.5 \mathrm{ml}$ ) was added the catalyst (TMEDA, TEDA or 18-crown-6; $0.3 \mathrm{mmol}$ ) and the mixture was magnetically stirred at room temperature for $30 \mathrm{~min}$. The bromide $1(591 \mathrm{mg}$, $3 \mathrm{mmol}$ ) was then added, and heated at $80^{\circ} \mathrm{C}$ with stirring. The extent of reaction was monitored by TLC. After $2 \mathrm{hr}$ the chilled reaction mixture was filtered, and the inorganic precipitate washed with ether. The combined organic solution was evaporated, and then the residual crude phthalimide was hydrolyzed with $47 \%-\mathrm{HBr}$. The product serine 4 was isolated by the usual work up. Ir and $\mathrm{nmr}$ spectra were identical with those of the authentic specimen. The other products 8 and 11 were purified by column chromatography (8; on alumina, eluent; benzene, and 11; on silica gel, eluent; benzene).

NMR and MS spectra of $8 ; \delta_{\text {Mesi }}^{\mathrm{CDCl}_{3}}: 2.20(3 \mathrm{H}$, $\left.\mathrm{COCH}_{3}\right), 3.42\left(3 \mathrm{H}, \mathrm{OCH}_{3}\right), 3.80\left(5 \mathrm{H}, \mathrm{COOCH}_{3}\right.$ and $\left.-\mathrm{CH}_{2}-\right), 5.23(1 \mathrm{H},-\mathrm{CH}) ; m / e: 176\left(\mathrm{M}^{+}\right)$. NMR and MS spectra of $11 ; \delta_{\text {MeSi }}^{\mathrm{CDCls}}: 3.35\left(3 \mathrm{H}, \mathrm{OCH}_{3}\right), 3.77(3 \mathrm{H}$, $\left.\mathrm{COOCH}_{3}\right), 3.80\left(2 \mathrm{H},-\mathrm{CH}_{2}-\right), 4.0(1 \mathrm{H},-\mathrm{CH}-) ; \mathrm{m} / \mathrm{e}$ : $175\left(\mathrm{M}^{+}\right)$.

Reaction of styrene bromohydrin with potassium thiocyanate; Typical procedure (Table II). Potassium thiocyanate $(264.5 \mathrm{mg}, 3.75 \mathrm{mmol})$, bromide $603 \mathrm{mg}$, $3 \mathrm{mmol}$ ) and catalyst (TMEDA; $34.9 \mathrm{mg},(0.3 \mathrm{mmol})$ were allowed to react at $80^{\circ} \mathrm{C}$ in acetonitrile. After $4 \mathrm{hr}$, the mixture was worked up. The crude product was purified by column chromatography on silica gel (eluent, benzene) to give the product. The nmr and mass spectra were consistent with those of the authentic sample derived from the cleavage of styrene oxide with KSCN. ${ }^{\text {) }}$

With crown ether, the reaction was performed in the same way as above except that the reaction mixture was heated for $30 \mathrm{~min}$. Product 12 purified by column chromatography was characterized spectroscopically.

IR $\nu_{\max }^{\mathrm{KRr}} \mathrm{cm}^{-1}: 2140(\mathrm{SCN}) ; \mathrm{MS} m / e: 179\left(\mathrm{M}^{+}\right)$; NMR $\delta_{\mathrm{MeSI}}^{\mathrm{CDCls}} 3.15\left(2 \mathrm{H},-\mathrm{CH}_{2} \mathrm{SCN}\right), 4.92(1 \mathrm{H},-\mathrm{CH}-)$, $7.26(5 \mathrm{H}, \mathrm{Ph})$.

Preparation of authentic samples of 9 and 10 . The direct displacement product 9 was produced by catalytic reduction of acetoxyacetophenone over $\mathrm{PtO}_{2}$ in methanol, which was derived from phenacyl bromide according to the literature. ${ }^{3)}$ The rearrangement product 10 was prepared by acetolysis of styrene oxide.

NMR spectrum of $9 ; \delta_{\text {MeSi }}^{\mathrm{CDCl}}: 1.97\left(3 \mathrm{H}, \mathrm{COCH}_{3}\right)$, $4.14\left(2 \mathrm{H},-\mathrm{CH}_{2}-\right), 4.87(1 \mathrm{H},-\mathrm{CH}-), 7.28(5 \mathrm{H}, \mathrm{Ph})$.

NMR spectrum of $10 ; \delta_{\mathrm{Mes}}^{\mathrm{CDCl} 1}: 2.06\left(3 \mathrm{H}, \mathrm{COCH}_{3}\right)$, $3.77\left(2 \mathrm{H},-\mathrm{CH}_{2}-\right), 5.77(1 \mathrm{H},-\mathrm{CH}-), 7.28(5 \mathrm{H}, \mathrm{Ph})$.

Both compounds 9 and 10 were acetylated with acetic anhydride in the presence of catalytic amounts of sulfuric acid to give the same 1,2-diacetoxyethylbenzene, yield $96.4 \%$, bp $100 \sim 102^{\circ} \mathrm{C} / 0.15 \mathrm{mmHg}$.

NMR $\delta_{\mathrm{MeSi}}^{\mathrm{CDCl}}: 1.99$ and $2.06\left(6 \mathrm{H}, 2 \times \mathrm{COCH}_{8}\right), 4.27$ $\left(2 \mathrm{H},-\mathrm{CH}_{2}-\right), 5.95(1 \mathrm{H},-\mathrm{CH}-), 7.30(5 \mathrm{H}, \mathrm{Ph})$.

\section{REFERENCES}

1) W. P. Weber and G. W. Gokel, "Phase Transfer Catalysis in Organic Synthesis," Springer Verlag, Berlin, 1977; C. M. Starks and C. Liotta, "Phase Transfer Catalysis," Academic Press Inc., New York, N. Y., 1978.

2) Y. Nakajima, R. Kinishi, J. Oda, and Y. Inouye, Bull. Chem. Soc. Japan, 50, 2025 (1977); Y. Nakajima, J. Oda, and Y. Inouye, Tetrahedron Lett., 3107 (1978).

3) H. Normant, T. Cuvingny, and P. Savignac, Synthesis, 805 (1975).

4) These results may possibly be related to an equilibrium between 9 and $\mathbf{1 0}$ involving acyl migration. However, this possibility can be excluded by the experimental fact that the rearrangement product 10 was not detected at all, when 9 was subjected to the same treatment as was employed for the reaction.

5) N. Watanabe, M. Okano, and S. Uemura, Bull. Chem. Soc. Japan, 47, 2745 (1974).

6) J. M. Stewart, J. Org. Chem., 28, 596 (1963).

7) W. L. F. Armarego, "Stereochemistry of Heterocyclic Compounds," Wiley Interscience, New York, 1977, Part 2, p. 172 ff. 